\title{
Electomagnetic absorption of composites based on epoxy resin and metallic iron nanoparticles
}

\author{
Roman V. Krekhno*' Alexander P. Safronov ${ }^{1,2}$, Anna I. Beketova ${ }^{1,2}$, Igor V. Beketov ${ }^{1,2}$ \\ ${ }^{1}$ Ural Federal University, Ekaterinburg, Russian Federation \\ ${ }^{2}$ Institute of Electrophysics UD RAS, Ekaterinburg, Russian Federation
}

\begin{abstract}
The heat losses originated from the electro-magnetic absorption in magnetic epoxy-based composites with embedded metallic iron nanoparicles were studied by Calvet microcalorimetry. Iron magnetic nanoparticles (MNPs) were synthesized by electrical explosion of wire (EEW) method; they were non-agglomerated, spherical in shape and had a weight average diameter $85 \mathrm{~nm}$. Composites based on the cured epoxy-dian resin contained MNPs in weight content varying from $10 \%$ up to $70 \%$. To study the heat loss in alterating magnetic field commercial Calvet microcalorimeter was equiped by two coils in the serial connection placed in the calorimeter cells; one of the coils contained a sample of composite the other was a reference. The electromagnetic adsorption was studied in the alternating magnetic field up to $1700 \mathrm{~A} / \mathrm{m}$ in $67-214 \mathrm{kHz}$ frequency range. The measured values of the specific power losses revealed linear dependence on iron MNPs content in composite and non-linear increasing function of the field frequency.
\end{abstract}

\section{Introduction}

Modern polymer composites are multicomponent systems comprising a polymer matrix and particulate filler material that impart various functional properties. The composite materials based on epoxy resins are of particular interest, since this class of composites has a mechanical strength, chemical resistance, high dielectric properties after curing, good adhesion to metals. Epoxy composites are promising materials for use in aviation and space industry. Magnetically filled polymer composites containing magnetically soft particles are widely used to produce magnetic screens for the absorption of electromagnetic radiation of various frequencies and coatings to protect instruments and sensors sensitive to electromagnetic radiation. At the present time there is a number of works devoted to the electro-magnetic absorption of polymer composites based on thermoplastic polymers with embedded magnetic particles [1-9].

The absorption of electromagnetic emission often means conversion of electro-magnetic energy to heat. Consequently, the direct measurement of the thermal power emitted by magnetic filled composites in the absorption of electromagnetic fields can be a precise quantitative assessment of the magnitude of the absorbed emission. Calorimetry is a direct experimental method for direct measurement of the heat evolution in various chemical and physico-chemical processes. Recently the usage of the modified Calvet microcalorimeter was reported for the measurement of specific power losses in the hyperthermia studies of ferrofluids $[10,11]$.

In the present work we intended to elaborate the direct microcalorimetry measurenets to evaluate heat losses of the epoxy-based solid polymeric composites with embedded iron magnetic nanoparticles (MNPs).

\section{Experimental}

The dual-component system of ED-20 (epoxy-diane resin based on diphenylolpropane) and a curing agent polyethylenepolyamine (PEPA) was used as a matrix for composite materials.

The metallic iron MNPs $\left(\mathrm{Ssp}=9.0 \mathrm{~m}^{2} / \mathrm{g}\right.$, weight average particle size $85 \mathrm{~nm}$ ) were synthesized by the electrical explosion of wire (EEW). The details of EEW method were given elsewhere [12-14]

For the preparation of a composite the iron powder was gradually filled in the resin ED-20 under continuous stirring. Epoxy resin was solidified at room temperature. The hardener PEPA was added to placing the composite in a mold and the resin began curing immediately thereafter. The samples were obtained in the form of cylinders $4 \mathrm{~mm}$ in diameter and $30 \mathrm{~mm}$ in length. Composites with increasing weight content of iron MNPs 10, 20, 30, 40, 50, 60, 70\% were prepared.

The powder X-ray diffraction (XRD) patterns were recorded using Bruker D8 Discover with $\mathrm{Cu} \mathrm{K}_{\alpha}$ radiation $(\lambda=1.542 \AA)$ with graphite monochromator. The Rietveld refinement of XRD patterns were performed using Topas-3 software. The morphology of MNPs was examined using JEOL JEM2100 transmission electron microscope (TEM) operating at $200 \mathrm{kV}$. The specific surface area of MNPs was measured by the low-temperature adsorption of nitrogen (Brunauer-Emett-Teller (BET) approach) using Micromeritics TriStar3000 analyzer. The magnetic measurements were carried out using (Cryogenics Ltd. VSM) vibrating sample magnetometer (VSM) at room

*Corresponding author: lipka-lipka-lipka@yandex.ru 
temperature for powder samples placed in a gelatine capsule. The magnetization values in a field of $1.8 \mathrm{~T}$ were designated as the saturation magnetization values $\left(\mathrm{M}_{\mathrm{s}}\right)$.

The Calvet microcalorimetry method was used to study the specific power losses of magnetically filled polymer composites in altering homogeneous magnetic fields. The commercial microcalorimeter was modified using solenoids with a number of turns of 12000 per meter, which were placed in calorimeter cells and serially connected to an alternating current source up to $150 \mathrm{~mA}$, as shown in Figure 1. The field intensity was $1700 \mathrm{~A} / \mathrm{m}$. The frequency range of sound-wave generator was $66-214 \mathrm{KHz}$. The sensitivity of calorimetric cells was $10^{-6} \mathrm{Joule} / \mathrm{sec}$.

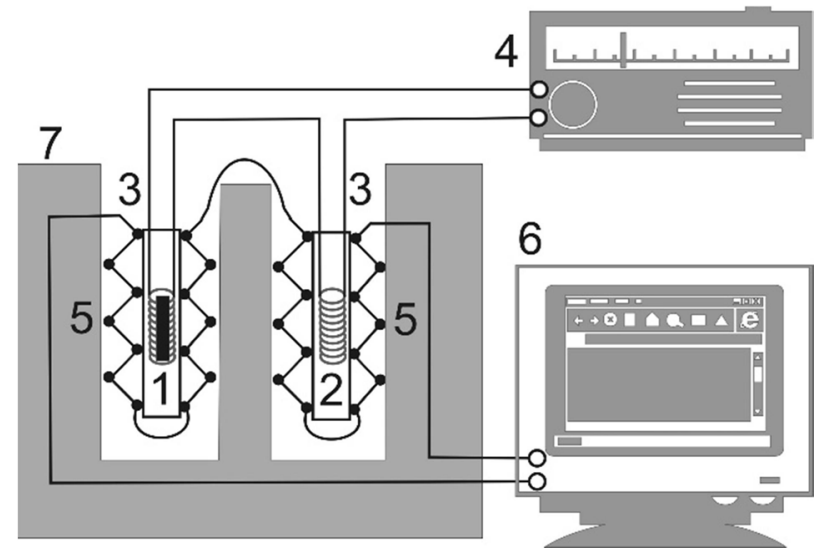

Fig. 1. Schematic diagram of the experimental setup for the microcalorimetry measurement of the heat losses of epoxy composites with iron MNPs in the alternating magnetic field. 1 - Calorimetric cell with the sample of composite. 2 Reference cell. 3 - Identical serially connected solenoids mounted in cells. 4 - Sound-wave generator. 5 - Identical differentially connected batteries of thermocouples (450 junctions in each). 6 - Computerized control unit for the measuring of calorimetry signal. 7 - Thermostat.

\section{Results and discussion}

Figure 2 presents TEM image of EEW iron MNPs used for the preparation of epoxy composites. It can be seen MNPs have a spherical shape. XRD plots are given in the inset in Figure 2. The iron MNPs had a phase composition of $98 \% \alpha \mathrm{Fe}$ and $2 \% \gamma \mathrm{Fe} . \alpha \mathrm{Fe}$ had a lattice period a $=2.866 \AA$, a coherent scattering region of 80 $\mathrm{nm}$. The dimensions of the coherent scattering regions are consistent with the particle diameters obtained in the analysis of micrographs.

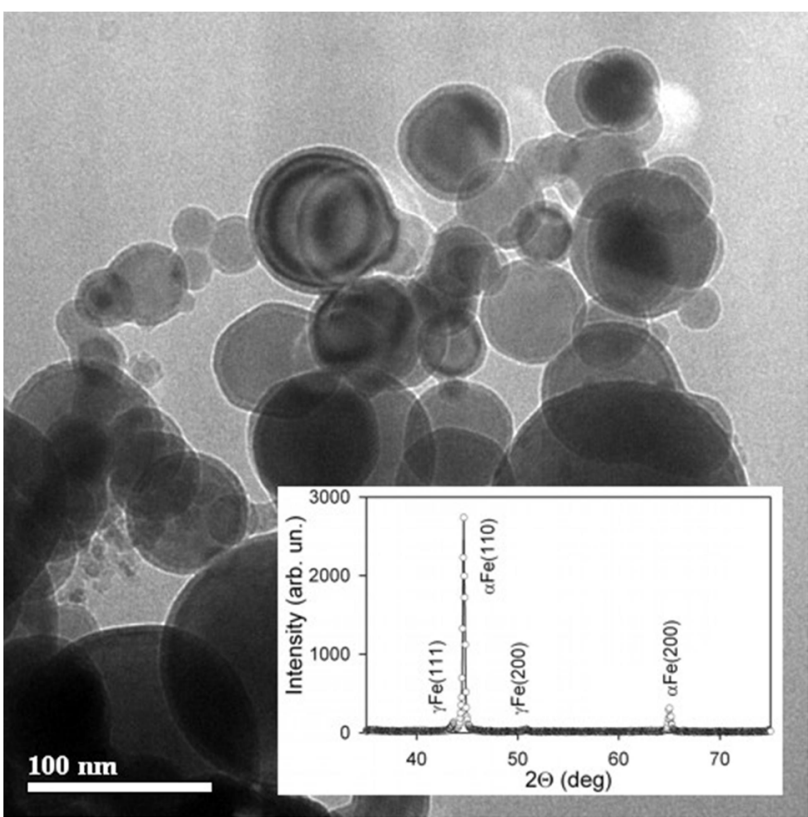

Fig. 2. TEM image of iron MNPs used for the preparation of epoxy composites. Inset - XRD plot of iron MNPs

Magnetization loops of ED-20 + Fe composites, recalculated per gram of composite, in comparison with Fe powder magnetization loop are presented in Figure 3.

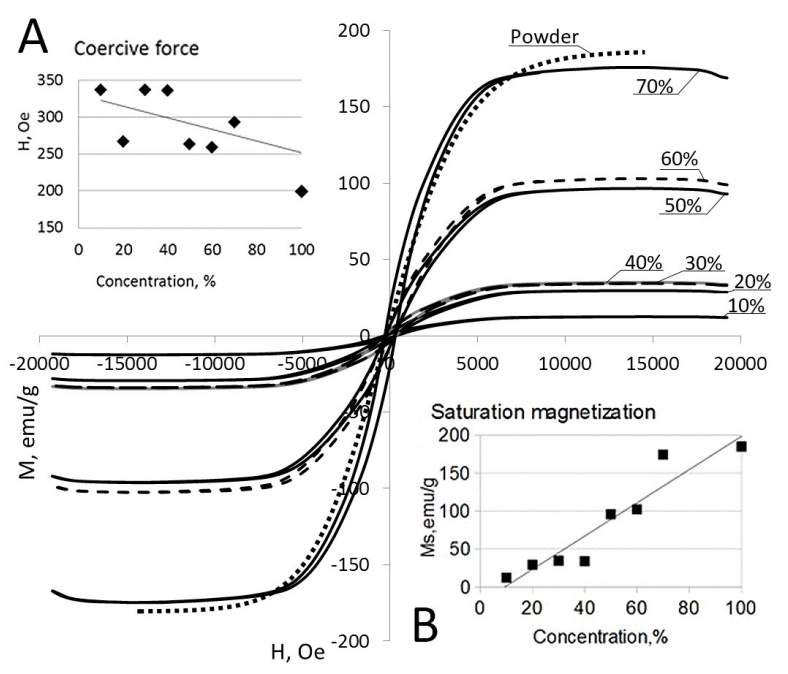

Fig. 3. Magnetization loops for epoxy composites with embedded iron MNPs. Inserts show the dependence of coercivity(A) and saturation magnetization(B) on Fe content in composite.

The comprehensive breakdown of this figure is summarized in the Table 1. The saturation magnetization increases linearly with the increase in the weight content of iron in the polymer composite. The coercive force alters in small limits, but generally has a tendency to decrease with increasing iron content, approaching the coercive force of the iron powder. 
Table 1. Magnetic parameters of epoxy composites with iron

\begin{tabular}{|c|c|c|c|}
\hline \multirow{2}{*}{$\% \mathrm{Fe}$} & $\begin{array}{c}\text { Saturation } \\
\text { magnetization }\end{array}$ & $\begin{array}{c}\text { Residual } \\
\text { magnetization }\end{array}$ & Coercivity \\
\cline { 2 - 4 } & $\mathrm{Ms}$, emu/g & $\mathrm{Mr}, \mathrm{emu} / \mathrm{g}$ & $\mathrm{Hc}, \mathrm{Oe}$ \\
\hline 10 & 12,4 & 1,27 & 337,2 \\
\hline 20 & 29,3 & 1,95 & 266,5 \\
\hline 30 & 34,6 & 3,69 & 337 \\
\hline 40 & 33,9 & 3,63 & 335,5 \\
\hline 50 & 95,8 & 6,76 & 262,9 \\
\hline 60 & 102,2 & 7,21 & 259 \\
\hline 70 & 174,3 & 18,8 & 293,5 \\
\hline 100 & 185 & 30 & 199,8 \\
\hline
\end{tabular}

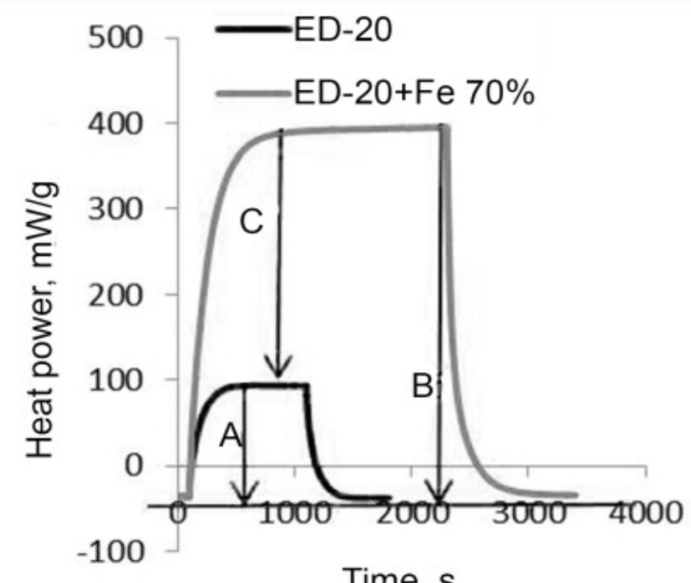

Time, s

Fig. 4. Heat evolution curves of pure epoxy resin ED-20 without filler and a composite ED-20 $+70 \% \mathrm{Fe}$ in an alternating magnetic field. A - thermal effect detected in pure epoxy resin. B - thermal effect detected in composite with $70 \% \mathrm{Fe}$ particles content. C - substraction results, which shows the remagnetization power loss in composite.

Figure 4 shows the examples of heat evolution curves registered in the measurement of specific power losses by calorimetry. The plots correspond to the power losses from ED-20 epoxy resin and to the power losses of a composite. The curves have the same shape due to the steps of measurement process. Initially they have the same baseline during the current generator offline time. Then, as the wave generator was turned on, the calorimetric signal increased due to the heat evolution in the cell. During this phase the signal eventually came to saturation. It meant that the thermal balance was established between the heating power in the cell and the dissipation of the heat from the cell due to the thermal conductivity of thermocouples. According to the theory of Calvet microcalorimetry the saturation value is proportional to the heating power evolved in the cell [15]. The proportionality constant was determined in the separately done calibration of the cell by the Joule heating. After the saturation of the calorimetric signal was established the current generator was turned off and the thermal emf of the calorimetric cell exponentially returned to the baseline.

The thermal response of the epoxy resin ED-20 without magnetic nanoparticles appears due to the Joule heat evolved in solenoids when an alternating voltage was applied to them. The heat evolution curve corresponding to a composite system, ED-20 + 70\% Fe is substantially higher than the curve corresponding to the pure epoxy resin ED-20. The difference in saturation values correspond to the evolution of heat due to the remagnetization of embedded MNPs in alternating magnetic field.

To calculate the specific power losses of the remagnetization of MNPs one have to calculate the net heat of pure ED-20 for use as a reference first. To do this, the value of the thermal effect, which was released on the saturation value was corrected by the baseline (Figure 4, arrow A). Further, in the same way the value of the thermal effect from the sample was calculated (Figure 4, arrow B). Finally, the heat power of epoxy ED-20 was subtracted from heat power of each sample and related to the weight of iron MNPs in the composite. The result of this subtraction can be visualized as an arrow $\mathrm{C}$ in Figure 4. This way the power losses for 7 samples of epoxy composites of different concentrations at different frequency of alternating field were obtained and given in Table 2 .

Table 2. Specific power losses during remagnetization of composites ED-20 + Fe with different concentrations at different frequencies, of an uniform magnetic field $1700 \mathrm{~A} / \mathrm{m}$.

\begin{tabular}{|c|c|c|c|c|}
\hline Frequency, $\mathrm{kHz}$ & 67 & 100 & 167 & 214 \\
\hline concentration, $\%$ & \multicolumn{5}{|c|}{ heat power, $\mathrm{mW} / \mathrm{g}$} \\
\hline 10 & 70,8 & 78,7 & 214,8 & 222,1 \\
\hline 20 & 63,2 & 78 & 217,2 & 241,7 \\
\hline 30 & 67,8 & 84,6 & 242,7 & 239,1 \\
\hline 40 & 65,5 & 83,6 & 245,9 & 276,3 \\
\hline 50 & 60,2 & 72,6 & 246,9 & \\
\hline 60 & 78 & 96,9 & 303,6 & 330,1 \\
\hline 70 & 72,6 & 98,3 & 313,1 & 397,7 \\
\hline
\end{tabular}

Dependencies of the specific power losses on the content of iron MNPs in composite and on the frequency of the applied field are presented in Figures 5 and 6 respectively

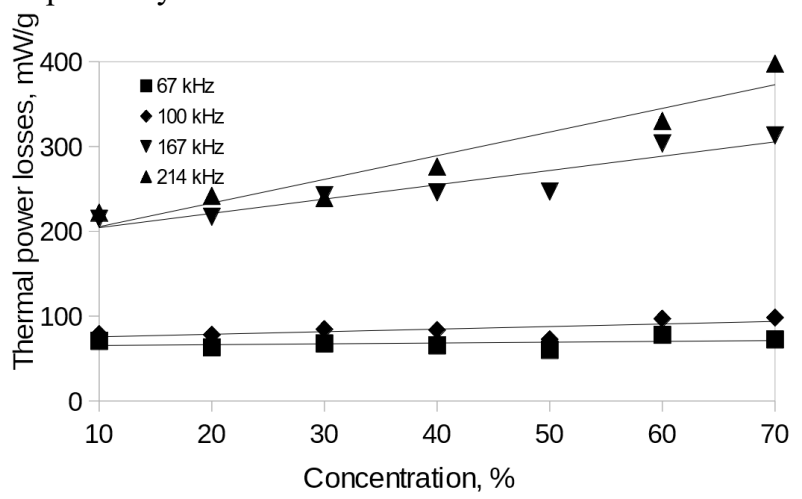

Figure 5. Specific thermal power losses per $1 \mathrm{~g}$ of $\mathrm{Fe}$ in remagnetization of magnetic filled samples in the alternating field $1700 \mathrm{~A} / \mathrm{m}$ at different frequencies, depending on the concentration of filler in the composite. 
Figure 5 shows that power losses at frequencies of $67 \mathrm{kHz}$ and $100 \mathrm{kHz}$ is much lower than the power losses at $167 \mathrm{kHz}$ and $214 \mathrm{kHz}$. At $67 \mathrm{kHz}$ and $100 \mathrm{kHz}$ power losses very slightly depend on MNPs content in the composite, while at $167 \mathrm{kHz}$ and $214 \mathrm{kHz}$ they substantially increase with increasing concentration of iron MNPs.

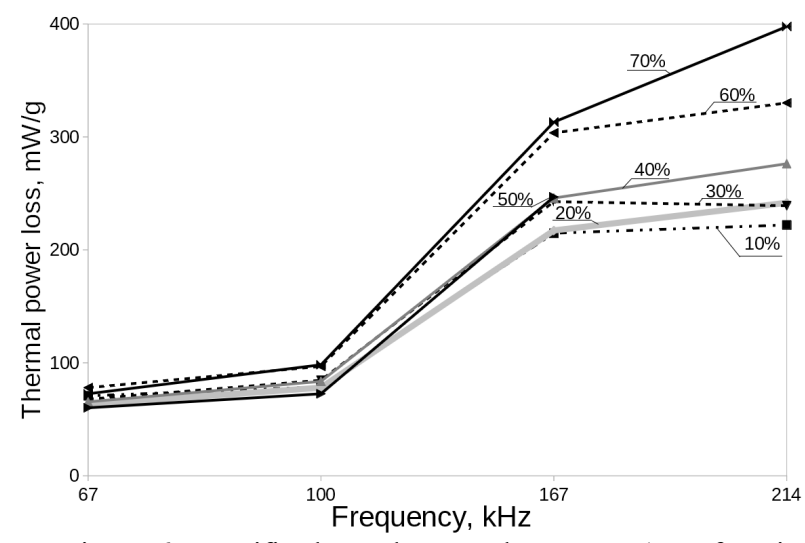

Figure 6. Specific thermal power losses per $1 \mathrm{~g}$ of $\mathrm{Fe}$ in remagnetization of magnetic filled samples of various concentrations, depending on the frequency of the uniform field $1700 \mathrm{~A} / \mathrm{m}$.

Figure 6 shows the thermal power losses in the remagnetization of magnetic filled composite of different concentrations, depending on the frequency. The data reveals that in general the thermal power loss increases with frequency. At the same time, the largest increase of heat occurs between $100 \mathrm{kHz}$ and $167 \mathrm{kHz}$. Moreover, at the frequency above $167 \mathrm{kHz}$, the significant discrepancy between the curves appear. At a frequency of $67 \mathrm{kHz}$ the difference in values is less than $10 \mathrm{~mW}$, while at a frequency of $214 \mathrm{kHz}$ the difference reaches $200 \mathrm{~mW}$.

\section{Conclusions}

1. Vibrational magnimetry method was used to obtain magnetization curves of epoxy resin composite filled with iron nanoparticles. It was found that the saturation magnetization increases linearly with the increase in the weight content of iron in the polymer composite. The coercive force decreases with increasing iron content, approaching the coercive force of the iron powder.

2. Calvet microcalorimetry method was used to study remagnetization power loss in magnetic filled polymer composites ED-20 $+\mathrm{Fe}$ MNPs with various concentrations and mass in an alternating magnetic field $1700 \mathrm{~A} / \mathrm{m}$. The heat dissipation power varied from 60 to $400 \mathrm{~mW} / \mathrm{g}$, reaching a maximum value of $400 \mathrm{~mW} / \mathrm{g}$ at a maximum frequency of $214 \mathrm{kHz}$ and with a maximum iron particle concentration of $70 \%$. A linear dependence of the heat power with the concentration of iron and nonlinear, monotonically increasing frequency dependence was found.

\section{Acknowledgements}

This work is supported in part by the project for basic research of UD RAS. The assistance of Shchipanova T. A. in the measurements of hysteresis loops for composites is appreciated.

\section{References}

1. K. Sonoda, M. Teirikangas, J. Juuti, Y. Moriya, H. Jantunen, JMMM, 323, 2281-2286 (2011)

2. I. Kong, S. Hj Ahmad, M. Hj Abdullah, D. Hui, A. Nazlim Yusoff, D. Puryanti ,JMMM 322, 3401-3409 (2010)

3. M.T. Sebastian, H. Jantunen, review, Int. J. Appl. Ceram. Technol. 7, 415-434 (2010)

4. T. Hu, J. Juuti, H. Jantunen, T. Vilkman, J. Eur. Ceram. Soc. 27 3997-4004 (2007)

5. J. Juuti, M. Teirikangas, K. Sonoda, H. Jantunen, T, Int. J. Appl. Ceram. Technol. 7, $452-460(2010)$

6. A.C. Barazs, T. Emrick, T.P. Russell, Science 314, 1107-1110 (2006)

7. E. Muhammad Abdul Jamal, P.A. Joy, P.Kurian, M.R. Anantharaman, MSE, B 156 24-31 (2009).

8. Ta-I Yang, Rene N.C. Brown, Leo C. Kempel, P. Kofinas, JMMM 320, 2714-2720 (2008)

9. T. Wang, Z. Liu, M. Lu, B. Wen, Q. Ouyang, Y. Chen, C. Zhu, P. Gao, C. Li, M. Cao, L. Qi, JAP 113, 024314 (2013)

10. Iu. P. Novoselova, A. P. Safronov, O. M. Samatov, G. V. Kurlyandskaya, - AIP Conference Proceedings 1767, 020016 (2016)

11. A.P. Safronov, O.M. Samatov, I.S. Tyukova, E.A. Mikhnevich , I.V. Beketov, JMMM 415, 24-29 (2016)

12. Yu.A. Kotov, Nanoparticle Research, 539-550 (2003)

13. G.V. Kurlyandskaya , S.M. Bhagat , A.P. Safronov, I.V. Beketov, A. Larrañaga, AIP Advances 1, 042122, (2011)

14. A.P. Safronov, G.V. Kurlyandskaya, A.A. Chlenova, M.V. Kuznetsov, D.N. Bazhin, I.V. Beketov, M.B. Sanchez-Ilarduya, A. MartinezAmesti, Langmuir, 30, 3243 (2014)

15. Calvet, E., Prat, H. Applications physicochimiques et biologiques. Paris. Masson and Cie (1956) 